\title{
Tunable single- and dual-wavelength SHG from diode- pumped PPKTP waveguides
}

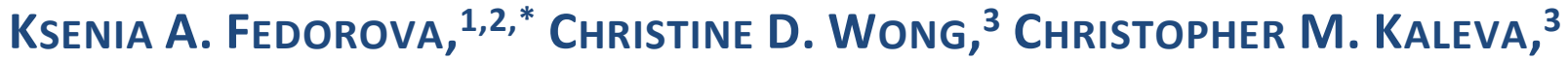 \\ Illa O. Bakshaev, ${ }^{4}$ Danill A. Livshits, ${ }^{4}$ Edik U. Rafailov ${ }^{1,2}$ \\ ${ }^{1}$ School of Engineering and Applied Science, Aston University, Aston Triangle, Birmingham, B4 7ET, UK \\ 2ITMO University, 49 Kronversky pr., St. Petersburg, 197101, Russia \\ ${ }^{3} A d v R$ Inc., 2310 University Way, Bldg. \#1-1 Bozeman, MT 59715, USA \\ 4Innolume GmbH, 11 Konrad-Adenauer-Allee, Dortmund, 44263, Germany \\ *Corresponding author: K.Fedorova@aston.ac.uk
}

Received XX Month XXXX; revised XX Month, XXXX; accepted XX Month XXXX; posted XX Month XXXX (Doc. ID XXXXX); published XX Month XXXX

\begin{abstract}
A compact, all-room-temperature, widely-tunable, continuous wave (CW) laser source in the green spectral region $(502.1 \mathrm{~nm}-544.2 \mathrm{~nm})$ with a maximum output power of $14.7 \mathrm{~mW}$ is demonstrated. This was made possible by utilizing second-harmonic generation (SHG) in a periodically poled potassium titanyl phosphate (PPKTP) crystal waveguide pumped by a quantum-well external-cavity fiber-coupled diode laser and exploiting the multimode-matching approach in nonlinear crystal waveguides. The dual-wavelength SHG in the wavelength region between $505.4 \mathrm{~nm}$ and $537.7 \mathrm{~nm}$ (with a wavelength difference ranging from $1.8 \mathrm{~nm}$ to $32.3 \mathrm{~nm}$ ) and sum-frequency generation in a PPKTP waveguide is also demonstrated. (C) 2016 Optical Society of America
\end{abstract}

OCIS codes: (140.3600) Lasers, tunable; (140.3515) Lasers, frequency doubled; (190.2620) Harmonic generation and mixing; (230.4320) Nonlinear optical devices; (230.7370) Waveguides; (140.5960) Semiconductor lasers.

http://dx.doi.org/10.1364/OL.99.099999

The development of dual- and multiple-wavelength lasers, particularly in the visible spectral region, is a very attractive research direction that aims to address a number of important applications, including biomedicine [1-3], spectroscopy [4], advanced imaging techniques [5-7], television, and laser projection technology [8]. Currently, many of these applications rely on bulky, expensive and complex-to-operate lasers with a number of laser sources required to cover broad visible spectral regions. Therefore, a compact, easy-to-use, cost-effective laser system, which could be tunable across the entire visible spectrum with a possibility to simultaneously generate multiple wavelengths, is of great interest for such applications.

To address this demand, semiconductor lasers with their small size, high efficiency, reliability and low cost can be exploited to cover ultra-broad near-infrared spectral ranges, depending on the composition of their active medium [9-11]. By combining many of the advantages of semiconductor lasers with the most attractive features of nonlinear crystals, the frequency conversion into the visible spectral region can be further exploited. In this respect, periodically poled nonlinear crystal waveguides [12], which take an advantage of a strong optical wave confinement with high optical intensities being maintained over long propagation lengths, can offer an order-of-magnitude increase in the infrared-to-visible conversion efficiency even at low pump powers, thus making the waveguided nonlinear optical conversion ideal for applications requiring CW or low-peak quasi-CW lasers [13]. Among several available periodically poled crystal waveguides, periodically poled lithium niobate [14-19] and periodically poled potassium titanyl phosphate (PPKTP) crystal waveguides [20-26] are usually used for highly efficient nonlinear wavelength conversion, particularly into the green spectral region. Moreover, the recently demonstrated multimode-matching approach [25] allows the realization of an all-room-temperature, compact, tunable visible laser source by second harmonic generation (SHG) in a periodically poled nonlinear crystal waveguide pumped by an infrared laser diode. By exploiting this technique, broad secondharmonic tunability up to $73 \mathrm{~nm}$ in the CW regime [27] and $27 \mathrm{~nm}$ in the pulsed regime [28] in the visible spectral region was achieved using a single PPKTP crystal waveguide and a single quantum-dot laser. This technique also allows multiplewavelength SHG in a single crystal waveguide, thus making this approach a very attractive way to replace different lasers used in applications such as super resolution imaging techniques with a single compact versatile laser source.

To date, several techniques have been shown to support the dual-wavelength operation of external-cavity diode lasers, 
including the use of a dual-wavelength volume-Bragg grating [29], a Y-slit [30], a V-shaped double-stripe mirror [31], or a dual-period holographic element [32] in the laser cavity. However, these techniques have some drawbacks in terms of tunability of mode separation, although some of them can offer some tuning by moving the position of a slit or a mirror. In contrast to the mentioned approaches, the dual-grating external-cavity diode laser configuration [33] can offer dual-wavelength laser output with broadly tunable mode separation, limited only by the spectral bandwidth of its gain element. All these methods of dualwavelength generation are of special interest for the terahertz generation [34] and the wavelength division multiplexing application, where the channels of information are encoded on light signals of different wavelengths, and also can be of great use for dual-color second harmonic generation into the visible spectral region.

In this work, we demonstrate the advantage of the use of the multimode-matching technique in nonlinear crystal waveguides for realization of compact broadly tunable single- and dualwavelength laser sources in the green spectral region by second harmonic generation (SHG).

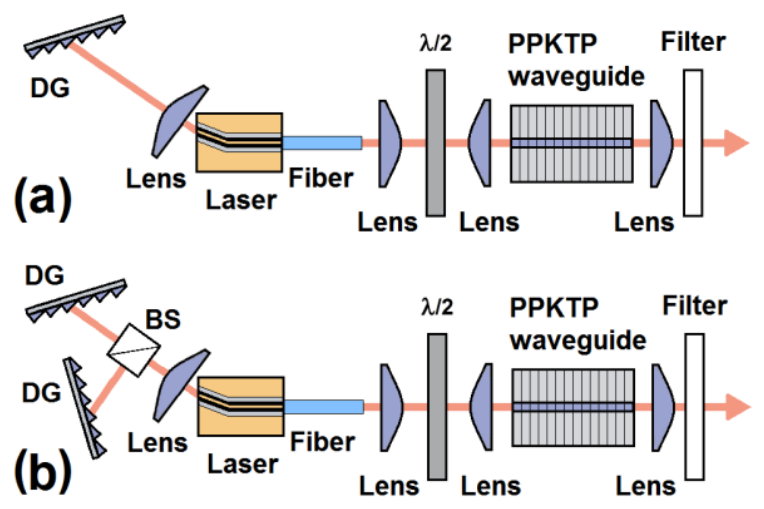

Fig. 1. Experimental setups of tunable (a) single- and (b) dualwavelength SHG in a PPKTP waveguide pumped by a fiber-coupled QW-ECDL (DG - diffraction grating, BS - beam splitter).

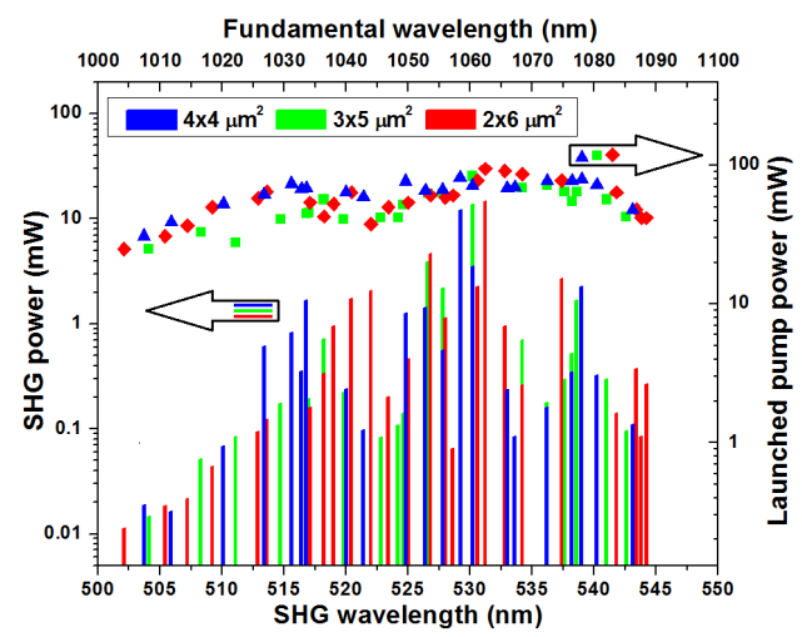

Fig. 2. Frequency-doubled and launched pump power vs. wavelength for three PPKTP waveguides with cross-sectional areas of $4 \times 4 \mu \mathrm{m}^{2}$, $3 \times 5 \mu \mathrm{m}^{2}$ and $2 \times 6 \mu \mathrm{m}^{2}$ obtained in the single-grating quasi-Littrow configuration.
The experimental setup consisted of a fiber-coupled quantumwell external-cavity diode laser (QW-ECDL) and a 15.5-mm long PPKTP crystal containing three waveguides with the crosssectional areas of $4 \times 4 \mu \mathrm{m}^{2}, 3 \times 5 \mu^{2}$ and $2 \times 6 \mu \mathrm{m}^{2}$, fabricated by the $\mathrm{Rb}$ ion-exchange technique $[35,13]$ that provided refractive index step $\Delta \mathrm{n} \approx 0.01$. The crystal was periodically poled for SHG at $\sim 1060$ $\mathrm{nm}$ and did not have antireflective (AR) coated facets. The periodic poling was performed after the waveguides were fabricated using an applied electric field to periodically invert the domains for the efficient frequency-doubling at $\sim 530 \mathrm{~nm}$. However, due to the fact that the poling quality could be different in waveguides with different widths, efficient SHG at $\sim 529.2 \mathrm{~nm}, 530.2 \mathrm{~nm}$ and $531.2 \mathrm{~nm}$ was observed from the waveguides with the crosssectional areas of $4 \times 4 \mu \mathrm{m}^{2}, 3 \times 5 \mu \mathrm{m}^{2}$, and $2 \times 6 \mu \mathrm{m}^{2}$, respectively. The QW laser chip had a length of $2.8 \mathrm{~mm}$, and the ridge waveguide with a width of $5 \mu \mathrm{m}$ was angled at $7^{\circ}$ relative to the normal of the AR-coated back facet. The QW laser chip was embedded in a 14pin open-butterfly package with the laser output from the front facet coupled into a single-mode polarization maintaining fiber PM-980. Second harmonic generation was investigated in two configurations using either a single diffraction grating with 1200 grooves/mm for single-wavelength tunable SHG (Fig.1(a)) or two similar diffraction gratings for dual-wavelength tunable frequency doubling (Fig.1(b)). In the case of the dual-grating quasi-Littrow configuration, the radiation emitted from the back facet of the laser chip was collected with a 40x AR-coated aspheric lens (numerical aperture of 0.55 ) and then split by a non-polarizing beam splitter into two beams with each one of them coupled onto a diffraction grating. The diffraction gratings reflected the first order of the diffracted beams back to the laser chip, thus allowing the simultaneous generation of two wavelengths from the QW-ECDL. The laser output in both configurations was collected with a 30x AR-coated aspheric lens (numerical aperture of 0.50) and then coupled into a PPKTP waveguide using a 40x AR-coated aspheric lens. A half-wave plate was used to adjust the polarization of the laser output for optimal SHG in the PPKTP waveguide crystal. The frequency-doubled output was collimated by a 30x AR-coated aspheric lens onto a power meter after a suitable filter at the fundamental wavelength. Both the laser and the nonlinear crystal were operating at room temperature $\left(20^{\circ} \mathrm{C}\right)$.

By utilizing the multimode-matching technique [25], we investigated the possibility of SHG wavelength tuning in these waveguides with different cross-sectional areas. With this approach, the phase-matching between a low-order fundamental and a high-order SHG modes allows the tunability of frequencydoubled light on the short wavelength side of the spectrum, and the interaction of a high-order fundamental with a low-order SHG modes corresponds to the tunability on the long wavelength side of the spectrum. The waveguides with the cross-sectional areas of $4 \times 4 \mu m^{2}, 3 \times 5 \mu m^{2}$ and $2 \times 6 \mu m^{2}$ demonstrated the secondharmonic tunability in the wavelength ranges $503.7 \mathrm{~nm}-543.1$ $\mathrm{nm}, 504.1 \mathrm{~nm}-542.6 \mathrm{~nm}$ and $502.1 \mathrm{~nm}-544.2 \mathrm{~nm}$, respectively (Fig. 2). The presented single-grating frequency-doubling scheme (Fig.1(a)) generated green light at $529.2 \mathrm{~nm}, 530.2 \mathrm{~nm}$ and 531.2 $\mathrm{nm}$ with an output power of $12 \mathrm{~mW}, 13.66 \mathrm{~mW}$ and $14.7 \mathrm{~mW}$, and a maximum conversion efficiency of $14.6 \%, 16.3 \%$ and $15.5 \%$, from the waveguides with the cross-sectional areas of $4 \times 4 \mu \mathrm{m}^{2}$, $3 \times 5 \mu \mathrm{m}^{2}$ and $2 \times 6 \mu \mathrm{m}^{2}$, respectively (Fig. 3(a)-(c)). The experimental results were numerically tanh ${ }^{2}$-fitted according to the depleted pump approximation with normalized conversion 
efficiencies of $185 \% / \mathrm{W}, 195 \% / \mathrm{W}$ and $182 \% / \mathrm{W}$ for the $4 \times 4 \mu \mathrm{m}^{2}$, $3 \times 5 \mu \mathrm{m}^{2}$ and $2 \times 6 \mu \mathrm{m}^{2}$ waveguides, respectively. In addition, the SHG wavelength tunability with the crystal temperature changing was also investigated, and the obtained spectra are depicted in Fig. $3(d)$. The continuous wavelength tuning in the wavelength range between $529.2 \mathrm{~nm}$ and $532.5 \mathrm{~nm}$ with similar conversion efficiencies in the PPKTP waveguides with the cross-sectional areas of $4 \times 4 \mu m^{2}, 3 \times 5 \mu m^{2}$ and $2 \times 6 \mu m^{2}$ was demonstrated by changing the temperature of the PPKTP crystal waveguides from $20^{\circ} \mathrm{C}$ to $90^{\circ} \mathrm{C}$ while simultaneously adjusting the output wavelength of the single-grating QW-ECDL.

With the dual-grating quasi-Littrow configuration it was possible to achieve dual-wavelength laser operation in the wavelength region $1010 \mathrm{~nm}$ - $1075 \mathrm{~nm}$ with a mode separation ranging between $2 \mathrm{~nm}$ and $65 \mathrm{~nm}$ by adjusting the angles of the diffraction gratings (Fig. 4). The multimode-matching approach [25] also allowed us to demonstrate the generation of two frequency-doubled wavelengths in a single PPKTP crystal waveguide in the visible spectral region (505.4 nm - $537.7 \mathrm{~nm}$ ) and the possibility to tune both of them simultaneously with a wavelength difference ranging from $1.8 \mathrm{~nm}$ to $32.3 \mathrm{~nm}$ (Fig. 5). The generation of the sum-frequency radiation was also observed (Fig. 5 ) indicating the concurrent generation of both infrared modes in the laser diode.

In the dual-grating frequency-doubling scheme, a maximum second harmonic output power of $8.4 \mathrm{~mW}$ at $531.2 \mathrm{~nm}$ with a conversion efficiency of $12 \%$ was obtained in the waveguide with cross-sectional area of $2 \times 6 \mu \mathrm{m}^{2}$ when both grating were tuned to a position to reflect the first order of the diffracted beam at the same wavelength back to the laser chip. This configuration also led to the broadening of the optical spectrum of SHG resulting in a full-width at half-maximum (FWHM) of $0.95 \mathrm{~nm}$ in comparison to the singlegrating laser configuration showing the FWHM of $0.71 \mathrm{~nm}$.
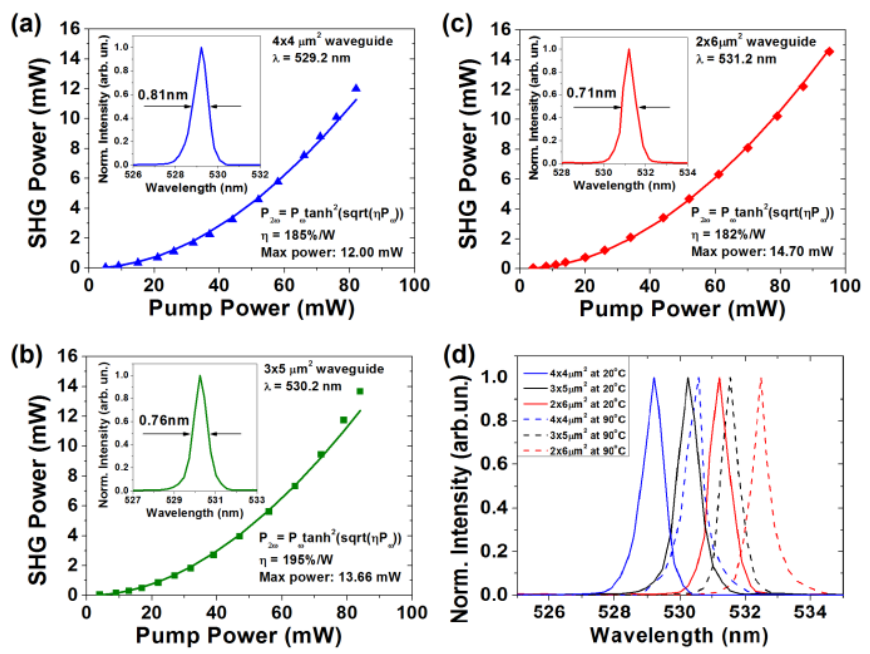

Fig. 3. (a), (b), (c) - Frequency-doubled output power versus launched pump power and optical spectra of the SHG at 529.2 $\mathrm{nm}, 530.2 \mathrm{~nm}$, and $531.2 \mathrm{~nm}$, correspondingly. (d) - Optical spectra of the SHG output tuned across the $529.2 \mathrm{~nm}-$ $532.5 \mathrm{~nm}$ wavelength range achieved by increasing the temperature of the PPKTP crystal from $20^{\circ} \mathrm{C}$ to $90^{\circ} \mathrm{C}$ while simultaneously tuning the QW-ECDL.
The demonstrated novel, compact, room-temperature laser source offering a broadband dual-wavelength tunability in the green spectral region is of great interest for a number of applications including Biomedicine and imaging techniques and offers the possibility for the future development of compact multicolor visible laser sources using a single laser diode and a single crystal waveguide.

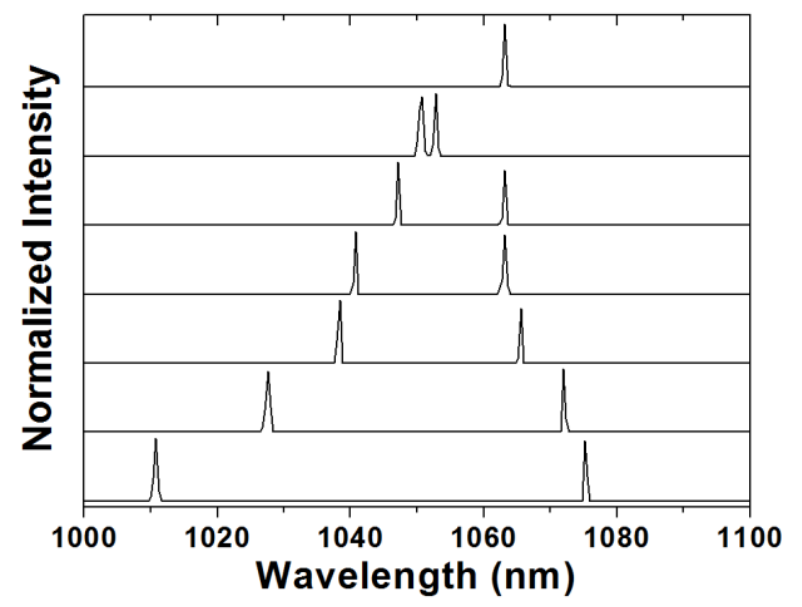

Fig. 4. Normalized optical spectra of tunable dual-wavelength fibercoupled QW-ECDL.

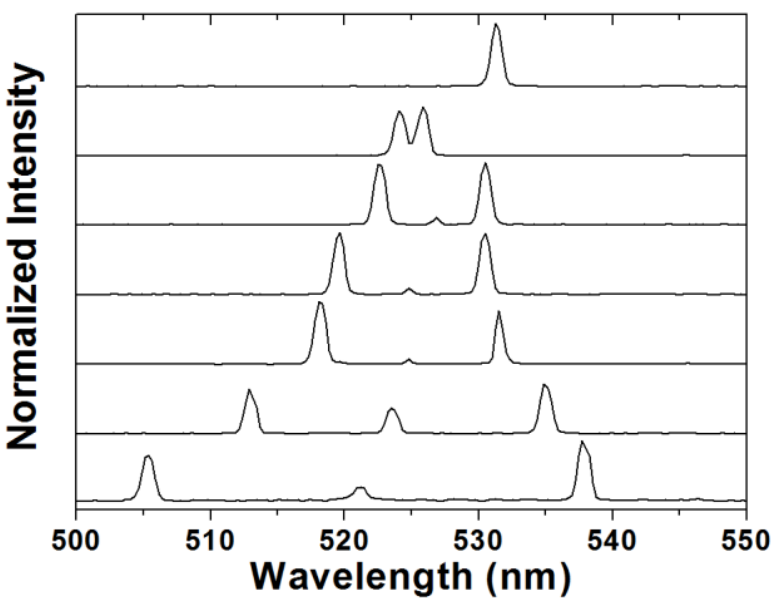

Fig. 5. Normalized optical spectra of tunable dual-wavelength second harmonic light in the waveguide with cross-sectional area of $2 \times 6 \mu \mathrm{m}^{2}$.

In this work we investigated the use of the multimode-matching technique in PPKTP crystal waveguides to achieve a broadly tunable single- and dual-color SHG output in the green spectral region (502.1 nm - $544.2 \mathrm{~nm}$ ) with a maximum output power of $14.7 \mathrm{~mW}$ and a maximum conversion efficiency of $16.3 \%$. The demonstrated single- and dual-wavelength compact versatile laser sources with the unique spectral coverage and wide tunability in the visible spectral region can replace available inefficient lasers and thus offers endless possibilities for existing applications in Biophotonics and medicine, which can take advantage of both the broad tunability in the visible spectral region and the simultaneous generation of several wavelengths.

The further optimization of the crystal waveguides and gain medium of the pump lasers can lead to the realization of 
significantly more power efficient laser devices and allow the extension of the generated wavelengths to cover the whole visible spectral region. The work on improvement of SHG conversion efficiency and further extension of operation to different spectral regions is currently underway.

\section{References}

1. S. Choudhary, K. Nouri, and L. Elsaie, Lasers Med. Sci. 24, 971 (2009).

2. J.F. Black, T. Tate, M. Keenan, E. Swan, U. Utzinger, J. Barton, in CLEO: 2015, OSA Technical Digest (online) (Optical Society of America, 2015), paper AM1J.7.

3. A. Boutier andJ.M. Most, in Laser Velocimetry in Fluid Mechanics, A. Boutier, ed. (Wiley, 2012).

4. B. Sumpf, M. Maiwald, K. Sowoidnich, and H.-D. Kronfeldt, Proc. SPIE 8718, 87180D (2013).

5. E. Simbuerger, T. Pflanz, and A. Masters, Confocal microscopy: new lasers enhance live cell imaging (Wiley, 2008), pp. 10-13.

6. T. Wilson, in Biomedical Photonics Handbook, Tuan Vo-Dinh, ed. (CRC Press, 2003).

7. S.Y. Leigh and J.T.C. Liu, Opt. Lett. 37, 2430 (2012).

8. M. Jansen, G.P. Carey, R. Carico, R. Dato, A.M. Earman, M.J. Finander, G. Giaretta, S. Hallstein, H. Hofler, C.P. Kocot, S. Lim, J. Krueger, A. Mooradian, G. Niven, Y. Okuno, F.G. Patterson, A. Tandon, and A. Umbrasas, Proc. SPIE 6489, 648908 (2007).

9. P.M. Varangis, H. Li, G.T. Liu, T.C. Newell, A. Stintz, B. Fuchs, K.J. Malloy, and L.F. Lester, Electron. Lett. 36, 1544 (2000).

10. K.A. Fedorova, M.A. Cataluna, I.L. Krestnikov, D.A. Livshits, E.U. Rafailov, Opt. Express 18, 19438 (2010).

11. H. Tabuchi and H. Ishikawa, Electron. Lett. 26, 742 (1990).

12. T. Suhara and M. Fujimura, Waveguide Nonlinear-Optic Devices (Springer, 2003).

13. B. Agate, E.U. Rafailov, W. Sibbett, S.M. Saltiel, K. Koynov, M. Tiihonen, S. Wang, F. Laurell, P. Battle, T. Fry, T. Roberts, and E. Noonan, in Frontiers in Planar Lightwave Circuit Technology, Vol. 216 of NATO Science Series II: Mathematics, Physics And Chemistry (Springer, 2006), pp. 189-227.

14. J. Burghoff, C. Grebing, S. Nolte, and A. Tünnermann, Appl. Phys. Lett. 89, 081108 (2006).

15. H.K. Nguyen, M.H. Hu, N. Nishiyama, N.J. Visovsky, Y. Li, K. Song, X. Liu, J. Gollier, L.C. Hughes, R. Bhat, and C.-E. Zah, IEEE Photon. Technol. Lett. 18, 682 (2006).

16. H. Jiang, G. Li, and X. Xu, Opt. Express 17, 16073 (2009).

17. J. Sun, Y. Gan, and C. Xu, Opt. Lett. 36, 549 (2011).

18. D. Jedrzejczyk, R. Gunter, K. Paschke, G. Erbert, G. Trankle, Appl. Phys. B 109, 33 (2012).

19. K.A. Fedorova, G.S. Sokolovskii, M. Khomylev, D.A. Livshits, and E.U. Rafailov, Opt. Lett. 39, 6672 (2014).

20. M. Rusu, E.U. Rafailov, R. Herda, O.G. Okhotnikov, S.M. Saltiel, P. Battle, S. McNeil, A.B. Grudinin, and W. Sibbett, Appl. Phys. Lett. 88, 121105 (2006).

21. C. Tu, Z. Huang, K. Lou, H. Liu, Y. Wang, Y. Li, F. Lu, and H.-T. Wang, Opt. Express 18, 25183 (2010).

22. F. Laurell, T. Calmano, S. Müller, P. Zeil, C. Canalias, and G. Huber, Opt. Express 20, 22308 (2012).

23. K.A. Fedorova, P.R. Battle, D.A. Livshits, E.U. Rafailov, Proc. SPIE 9347, 93470D (2015).

24. C. Chen, C.E. Rüter, M.F. Volk, C. Chen, Z. Shang, Q. Lu, S. Akhmadaliev, S. Zhou, F. Chen, and D. Kip, Opt. Express 24, 16434 (2016).

25. K.A. Fedorova, G.S. Sokolovskii, P.R. Battle, D.A. Livshits, and E.U. Rafailov, Laser Phys. Lett. 9, 790 (2012).

26. E.U. Rafailov, D.J.L. Birkin, W. Sibbett, P. Battle, T. Fry, and D. Mohatt, Opt. Lett. 26, 1961 (2001)

27. K.A. Fedorova, G.S. Sokolovskii, P.R. Battle, D.A. Livshits, and E.U. Rafailov, Opt. Lett. 40, 835 (2015).
28. K.A. Fedorova, G.S. Sokolovskii, D.I. Nikitichev, P.R. Battle, I.L. Krestnikov, D.A. Livshits, and E.U. Rafailov, Opt. Lett. 38, 2835 (2013).

29. S.A. Zolotovskaya, V.I. Smirnov, G.B. Venus, L.B. Glebov, and E.U. Rafailov, IEEE Photon. Technol. Lett. 21, 1093 (2009).

30. A. Biebersdorf, C. Lingk, M. De Giorgi, J. Feldmann, J. Sacher, M. Arzberger, C. Ulbrich, G. Böhm, M.-C. Amann, and G. Abstreiter, J. Phys. D: Appl. Phys. 36, 1928 (2003).

31. C.L. Pan and C.L. Wang, Opt. Quantum Electron. 28, 1239 (1996).

32. V. Zambon, M. Piche, and N. McCarthy, Opt. Commun. 264, 180 (2006).

33. R. Leyman, D. Carnegie, K. Fedorova, N. Bazieva, S. Schulz, C. Reardon, E. Clarke, E. Rafailov, CLEO/Europe-EQEC 2013, CC-P.5, Munich, Germany (2013).

34. S. Hoffmann and M.R. Hofmann, Laser Photon. Rev. 1, 44 (2007).

35. J.D. Bierlein, A. Ferretti, L.H. Brixner, and W.Y. Hsu, Appl. Phys. Lett. 50, 1216 (1987). 


\section{Full References}

1. S. Choudhary, K. Nouri, L. Elsaie, "Photodynamic therapy in dermatology: a review," Lasers Med. Sci. 24, 971-980 (2009).

2. J. F. Black, T. Tate, M. Keenan, E. Swan, U. Utzinger, J. Barton, "A Six-Color Four Laser Mobile Platform for Multi-Spectral Fluorescence Imaging Endoscopy," in CLEO: 2015, OSA Technical Digest (online) (Optical Society of America, 2015), paper AM11.7.

3. A. Boutier, J. M. Most, (2012) Laser Doppler Velocimetry, in Laser Velocimetry in Fluid Mechanics (ed A. Boutier), John Wiley \& Sons, Inc., Hoboken, NJ, USA.

4. B. Sumpf, M. Maiwald, K. Sowoidnich, H.-D. Kronfeldt, "Miniaturized diode laser based light sources for in-situ shifted excitation Raman difference spectroscopy," Proc. SPIE 8718, 87180D (2013).

5. E. Simbuerger, T. Pflanz, A. Masters, "Confocal microscopy: new lasers enhance live cell imaging," Physics' Best (Wiley-VCH Verlag GmbH \& Co. KGaA, Weinheim.), pp. 10-13 (2008).

6. T. Wilson, "Confocal Microscopy," Ch. 10 in Biomedical Photonics Handbook, Tuan Vo-Dinh (ed.), CRC Press, Boca Raton, Florida (2003)

7. S.Y. Leigh, J.T.C. Liu, "Multi-color miniature dual-axis confocal microscope for point-of-care pathology," Opt. Lett. 37, 2430-2432 (2012).

8. M. Jansen ; G. P. Carey ; R. Carico ; R. Dato ; A. M. Earman ; M. J. Finander ; G. Giaretta ; S. Hallstein ; H. Hofler ; C. P. Kocot ; S. Lim ; J. Krueger ; A. Mooradian ; G. Niven ; Y. Okuno ; F. G. Patterson ; A. Tandon ; A. Umbrasas; Visible laser sources for projection displays. Proc. SPIE 6489, Projection Displays XII, 648908 (February 06, 2007);

9. P. M. Varangis, H. Li, G. T. Liu, T. C. Newell, A. Stintz, B. Fuchs, K. J. Malloy, L. F. Lester, Electron. Lett. 36, 1544 (2000).

10. K.A. Fedorova, M.A. Cataluna, I.L. Krestnikov, D.A. Livshits, E.U. Rafailov, Opt. Express 18(18), 19438-19443 (2010).

11. H. Tabuchi, H. Ishikawa, "External grating tunable MQW laser with wide tuning range of $240 \mathrm{~nm}$," Electron. Lett. 26(11), 742-743 (1990).

12. T. Suhara, M. Fujimura, Waveguide Nonlinear-Optic Devices (Springer, Berlin, 2003).

13. B. Agate, E.U. Rafailov, W. Sibbett, S.M. Saltiel, K. Koynov, M. Tiihonen, S. Wang, F. Laurell, P. Battle, T. Fry, T. Roberts, E. Noonan, "Efficient frequency-doubling of femtosecond pulses in waveguide and bulk nonlinear crystals: Design, fabrication, theory and experiment," in Frontiers in Planar Lightwave Circuit Technology. NATO Sci. Ser. II: Math. Phys. Chem. 216, pp.189-227 (Springer, 2006).

14. J. Burghoff, C. Grebing, S. Nolte, and A. Tünnermann, "Efficient frequency doubling in femtosecond laserwritten waveguides in lithium niobate," Appl. Phys. Lett. 89(8), 081108 (2006).

15. H.K. Nguyen, M.H. Hu, N. Nishiyama, N.J. Visovsky, Y. Li, K. Song, X. Liu, J. Gollier, L.C. Hughes, R. Bhat, and C.-E. Zah, "107-mW low-noise greenlight emission by frequency doubling of a reliable 1060-nm DFB semiconductor laser diode," IEEE Photon. Technol. Lett. 18(5), 682-684 (2006).

16. $\mathrm{H}$. Jiang, G. Li, and X. Xu, "Highly efficient single-pass second harmonic generation in a periodically poled $\mathrm{MgO}: \mathrm{LiNbO}_{3}$ waveguide pumped by a fiber laser at $1111.6 \mathrm{~nm}$," Opt. Express 17, 16073-16080 (2009).

17. J. Sun, Y. Gan, and C. Xu, "Efficient green-light generation by protonexchanged periodically poled $\mathrm{MgO}: \mathrm{LiNbO}_{3}$ ridge waveguide," Opt. Lett. 36, 549-551 (2011).

18. D. Jedrzejczyk, R. Gunter, K. Paschke, G. Erbert, G. Trankle, "Diode laser frequency doubling in a ppMgO:LN ridge waveguide: influence of structural imperfections, optical absorption and heat generation," Applied Physics B 109(1), 33-42 (2012).

19. K.A. Fedorova, G.S. Sokolovskii, M. Khomylev, D.A. Livshits, and E.U. Rafailov, "Efficient yellow-green light generation at $561 \mathrm{~nm}$ by frequency-doubling of a QD-FBG laser diode in a PPLN waveguide," Opt. Lett. 39, 6672-6674 (2014).

20. M. Rusu, E.U. Rafailov, R. Herda, O.G. Okhotnikov, S.M. Saltiel, P. Battle, S. McNeil, A.B. Grudinin, W. Sibbett, "Efficient generation of green and UV light in a single PP-KTP waveguide pumped by a compact all-fiber system," Applied Physics Letters 88, 121105 (2006).

21. C. Tu, Z. Huang, K. Lou, H. Liu, Y. Wang, Y. Li, F. Lu, H.-T. Wang, "Efficient green-light generation by frequency doubling of a picosecond all-fiber ytterbium-doped fiber amplifier in PPKTP waveguide inscribed by femtosecond laser direct writing," Optics Express 18(24), 25183-25191 (2010).

22. F. Laurell, T. Calmano, S. Müller, P. Zeil, C. Canalias, and G. Huber, "Laserwritten waveguides in KTP for broadband Type II second harmonic generation," Opt. Express 20(20), 22308-22313 (2012).

23. K. A. Fedorova ; P. R. Battle ; D. A. Livshits ; E. U. Rafailov; $517 \mathrm{~nm}-538 \mathrm{~nm}$ tunable second harmonic generation in a diode-pumped PPKTP waveguide crystal. Proc. SPIE 9347, Nonlinear Frequency Generation and Conversion: Materials, Devices, and Applications XIV, 93470D (February 27, 2015);

24. C. Chen, C.E. Rüter, M.F. Volk, C. Chen, Z. Shang, Q. Lu, S. Akhmadaliev, S Zhou, F. Chen, D. Kip, "Second harmonic generation of diamond-blade diced KTiOPO4 ridge waveguides," Opt. Express 24(15), 16434-16439 (2016).

25. K.A. Fedorova, G.S. Sokolovskii, P.R. Battle, D.A. Livshits, E.U. Rafailov, "Green-to-red tunable SHG of a quantum-dot laser in a PPKTP waveguide," Laser Physics Letters, 9, 790-795 (2012).

26. E. U. Rafailov, D. J. L. Birkin, W. Sibbett, P. Battle, T. Fry, and D. Mohatt, "Efficient frequency doubling of a pulsed laser diode by use of a periodically poled KTP waveguide crystal with Bragg gratings," Opt. Lett. 26, 1961-1962 (2001)

27. K.A. Fedorova, G.S. Sokolovskii, P.R. Battle, D.A. Livshits, E.U. Rafailov, "574-647 nm wavelength tuning by second-harmonic generation from diode-pumped PPKTP waveguides," Optics Letters 40(5), 835-838 (2015).

28. K.A. Fedorova, G.S. Sokolovskii, D.I. Nikitichev, P.R. Battle, I.L. Krestnikov, D.A. Livshits, E.U. Rafailov, "Orange-to-red tunable picosecond pulses by frequency doubling in a diode-pumped PPKTP waveguide," Optics Letters 38 (15), pp. 2835-2837 (2013).

29. S.A. Zolotovskaya, V.I. Smirnov, G.B. Venus, L.B. Glebov, E.U. Rafailov, "Two-color output from InGaAs laser with multiplexed reflective Bragg mirror," IEEE Photon. Technol. Lett. 21(15), 1093-1095 (2009).

30. A. Biebersdorf, C. Lingk, M. De Giorgi, J. Feldmann, J. Sacher, M. Arzberger, C. Ulbrich, G. Böhm, M.-C. Amann, G. Abstreiter, "Tunable single and dual mode operation of an external cavity quantum-dot injection laser," J. Phys. D Appl. Phys. 36(16), 1928-1930 (2003).

31. C.L. Pan, C.L. Wang, "A novel tunable dual-wavelength external-cavity laser diode array and its applications," Opt. Quantum Electron. 28, 12391257 (1996).

32. V. Zambon, M. Piche, N. McCarthy, "Tunable dual-wavelength operation of an external cavity semiconductor laser," Optics Communication 264(1) 180-186 (2006).

33. R. Leyman, D. Carnegie, K. Fedorova, N. Bazieva, S. Schulz, C. Reardon, E. Clarke, E. Rafailov, "THz emission from quantum dot-based THz antennas pumped by a quantum-dot tunable laser diode," CLEO/Europe-EQEC 2013, CC-P.5, Munich, Germany (2013).

34. S. Hoffmann, M.R. Hofmann, "Generation of Terahertz radiation with two color semiconductor lasers," Laser Photonics Reviews 1(1), $44-56$ (2007).

35. J.D. Bierlein, A. Ferretti, L.H. Brixner, W.Y. Hsu, "Fabrication and characterization of optical waveguides in KTiOPO4," Appl. Phys. Lett. 50(18), 1216-1218 (1987) 